\title{
Intracellular lysophosphatidic acid influences cell migration
}

\author{
Regina Stöber ${ }^{1}$
}

Received: 9 November 2017 / Accepted: 13 November 2017 / Published online: 24 November 2017

c) Springer-Verlag GmbH Germany, part of Springer Nature 2017

Altered cellular metabolism has been intensively studied in relation to carcinogenesis and tumor development (Currie et al. 2013; Pavlova and Thompson 2016; Santos and Schulze 2012). However, relatively, little is known about the mechanisms how choline metabolism influences the tumor phenotype (Okazaki et al. 2010; Glunde et al. 2015; Granata et al. 2014, 2015; Marchan et al. 2012; Ghallab 2014; Hassan 2017). In the September issue of Cancer Research, a new concept has been presented how choline metabolism influences the phenotype of tumor cells (Marchan et al. 2017): the intracellular concentration of the signaling lipid lysophosphatidic acid (LPA) is critical for tumor cell migration. In the first step, the authors overexpressed and knocked down glycerol-3-phosphate acetyltransferase 1 (GPAM) in tumor cell lines. This influenced intracellular concentrations of LPA, which was associated with higher or lower migration activity. However, the casual relationship between intracellular LPA and migration was established by an elegant method. This technique allows the direct introduction of LPA into cells by a cationic transfection reagent (Marchan et al. 2017). This experiment formally proved that tumor cell migration is stimulated by increased intracellular LPA concentrations. This finding is conceptually new because so far LPA was only known to act via extracellular receptors.

In the past decades, numerous factors have been shown to influence prognosis of carcinomas, such as the humoral and cellular immune system (Schmidt et al. 2008; Heimes et al. 2017a, b; Godoy et al. 2014), cytoskeleton (Hellwig et al. 2016; Stock et al. 2015), redox system (Cadenas et al. 2010), and circulation clock-associated factors (Cadenas et al. 2014). The observation that intracellular choline metabolites influence tumor cell migration and adhesion is relatively new and the responsible mechanisms have not yet been fully elucidated (Stewart et al. 2012; Marchan et al.

Regina Stöber

stoeber@ifado.de

1 IfADo-Leibniz Research Centre for Working Environment and Human Factors, TU Dortmund, Ardeystr. 67,

44139 Dortmund, Germany
2012; Lesjak et al. 2014). The recently discovered mechanism of intracellular LPA adds a new aspect of how choline metabolism contributes to the phenotype of tumor cells.

\section{References}

Cadenas C, Franckenstein D, Schmidt M et al (2010) Role of thioredoxin reductase 1 and thioredoxin interacting protein in prognosis of breast cancer. Breast Cancer Res 12(3):R44

Cadenas C, van de Sandt L, Edlund K, Lohr M, Hellwig B, Marchan R, Schmidt M, Rahnenführer J, Oster H, Hengstler JG (2014) Loss of circadian clock gene expression is associated with tumor progression in breast cancer. Cell Cycle 13(20):3282-3291

Currie E, Schulze A, Zechner R, Walther TC, Farese RV Jr (2013) Cellular fatty acid metabolism and cancer. Cell Metab 18:153-161

Ghallab A (2014) Highlights in tumor metabolome research: choline metabolism influences integrin expression and supports cell attachment. EXCLI J 13:856-858

Glunde K, Penet MF, Jiang L, Jacobs MA, Bhujwalla ZM (2015) Choline metabolism-based molecular diagnosis of cancer: an update. Expert Rev Mol Diagn 15:735-747

Godoy P, Cadenas C, Hellwig B et al (2014) Interferon-inducible guanylate binding protein (GBP2) is associated with better prognosis in breast cancer and indicates an efficient $\mathrm{T}$ cell response. Breast Cancer 21(4):491-499. doi: https://doi.org/10.1007/ s12282-012-0404-8

Granata A, Nicoletti R, Tinaglia V, De Cecco L, Pisanu ME, Ricci A et al (2014) Choline kinase-alpha by regulating cell aggressiveness and drug sensitivity is a potential druggable target for ovarian cancer. Br J Cancer 110:330-340

Granata A, Nicoletti R, Perego P, Iorio E, Krishnamachary B, Benigni $F$ et al (2015) Global metabolic profile identifies choline kinase alpha as a key regulator of glutathione-dependent antioxidant cell defense in ovarian carcinoma. Oncotarget 6:11216-11230

Hassan R (2017) Highlight report: The EDI3-GPAM axis in tumor cell migration. EXCLI J 16:1148-1149

Heimes AS, Madjar K, Edlund K, Battista MJ, Almstedt K, Elger T, Krajnak S, Rahnenführer J, Brenner W, Hasenburg A, Hengstler JG, Schmidt M (2017a) Subtype-specific prognostic impact of different immune signatures in node-negative breast cancer. Breast Cancer Res Treat 165(2):293-300

Heimes AS, Madjar K, Edlund K, Battista MJ, Almstedt K, Gebhard S, Foersch S, Rahnenführer J, Brenner W, Hasenburg A, Hengstler JG, Schmidt M (2017b) Prognostic significance of interferon regulating factor 4 (IRF4) in node-negative breast cancer. J Cancer Res Clin Oncol 143(7):1123-1131 
Hellwig B, Madjar K, Edlund K et al (2016) Epsin family member 3 and ribosome-related genes are associated with late metastasis in estrogen receptor-positive breast cancer and long-term survival in non-small cell lung cancer using a genome-wide identification and validation strategy. PLoS One 11(12):e0167585

Lesjak MS, Marchan R, Stewart JD, Rempel E, Rahnenführer J, Hengstler JG (2014) EDI3 links choline metabolism to integrin expression, cell adhesion and spreading. Cell Adh Migr 8:499-508

Marchan R, Lesjak MS, Stewart JD, Winter R, Seeliger J, Hengstler JG (2012) Choline-releasing glycerophosphodiesterase EDI3 links the tumor metabolome to signalling network activities. Cell Cycle 11:4499-4506

Marchan R, Büttner B, Lambert J, Edlund K, Glaser I, Blaszkewicz $\mathrm{M}$ et al (2017) Glycerol-3-phosphate acyltransferase 1 promotes tumor cell migration and poor survival in ovarian carcinoma. Cancer Res 77:4589-4601

Okazaki Y, Ohshima N, Yoshizawa I, Kamei Y, Mariggio S, Okamoto K et al (2010) A novel glycerophosphodiester phosphodiesterase, GDE5, controls skeletal muscle devevolpment via a non-enzymatic mechanism. J Biol Chem 285:27652-27663
Pavlova NN, Thompson CB (2016) The emerging hallmarks of cancer metabolism. Cell Metab 23:27-47

Santos CR, Schulze A (2012) Lipid metabolism in cancer. FEBS J 279:2610-2623

Schmidt M, Böhm D, von Törne C, Steiner E, Puhl A, Pilch H, Lehr HA, Hengstler JG, Kölbl H, Gehrmann M (2008) The humoral immune system has a key prognostic impact in node-negative breast cancer. Cancer Res 68(13):5405-5413

Stewart JD, Marchan R, Lesjak MS, Lambert J, Hergenroeder R, Ellis JK et al (2012) Choline-releasing glycerophosphodiesterase EDI3 drives tumor cell migration and metastasis. Proc Natl Acad Sci USA 109:8155-8160

Stock AM, Klee F, Edlund K, Grinberg M, Hammad S, Marchan R, Cadenas C, Niggemann B, Zänker KS, Rahnenführer J, Schmidt M, Hengstler JG, Entschladen F (2015) Gelsolin is associated with longer metastasis-free survival and reduced cell migration in estrogen receptor-positive breast cancer. Anticancer Res 35(10):5277-5285 